\title{
บusisersaly
}

\section{Investigating the healthiness of food products on promotion: market brands and own brands}

Beacom, E., Hollywood, L. E., McLaughlin, C., Furey, S., Price, RK., McMahon-Beattie, U., \& Burns, A. (2021). Investigating the healthiness of food products on promotion: market brands and own brands. British Food Journal, (0007-070X). https://doi.org/10.1108/BFJ-04-2021-0371

Link to publication record in Ulster University Research Portal

\section{Published in:}

British Food Journal

Publication Status:

Published online: 26/08/2021

DOI:

10.1108/BFJ-04-2021-0371

\section{Document Version}

Author Accepted version

\section{General rights}

Copyright for the publications made accessible via Ulster University's Research Portal is retained by the author(s) and / or other copyright owners and it is a condition of accessing these publications that users recognise and abide by the legal requirements associated with these rights.

\section{Take down policy}

The Research Portal is Ulster University's institutional repository that provides access to Ulster's research outputs. Every effort has been made to ensure that content in the Research Portal does not infringe any person's rights, or applicable UK laws. If you discover content in the Research Portal that you believe breaches copyright or violates any law, please contact pure-support@ulster.ac.uk. 


\section{Pemerald PUBLISHING}

'This author accepted manuscript is deposited under a Creative Commons Attribution Non-commercial 4.0 International (CC BY-NC) licence. This means that anyone may distribute, adapt, and build upon the work for non-commercial purposes, subject to full attribution. If you wish to use this manuscript for commercial purposes, please contact permissions@emerald.com.' 
Investigating the healthiness of food products on promotion: market brands and own brands

\begin{abstract}
Purpose: The purpose of this study was to investigate the proportionality of market brand (MB) foods versus supermarket own brand (OB) foods sold on promotion, and to compare their healthiness.
\end{abstract}

Methodology: An existing dataset containing nutritional information about a variety of foods on promotion $(\mathrm{n}=6776)$ from forty-eight stores across eight retail chains in Northern Ireland (NI) was reanalysed. Product healthiness was measured using a score aligned to the Food Standards Agency's Front of Pack nutrient labelling system. MBs and OBs were considered as a whole, and in their respective subsets - international/national and regional MBs, and premium, mid-market and value tiered OBs.

Findings: Results found a balance in favour of health (52.4\% amber/green versus $47.6 \%$ red) across retailers' promotions in NI. Further, OB products were often found to be superior to MBs with regards to overall healthfulness, and regional brands were found to be less healthy than international/national brands.

Practical implications: Retailers should communicate the comparative healthiness of their OBs in comparison to $\mathrm{MB}$ alternatives, in addition to communicating comparative price savings. There is opportunity for retailers to increase visibility of mid-market and value OB tiers, and for regional MBs to improve the nutritional profile of products in line with the consumer trend for health.

Research implications: Findings rationale further retail research to compare nutritionally OB and MB product types, and further consumer research regarding important attributes of OBs.

Originality/value: This study provides a contribution by using data on OBs and MBs on promotion, and by investigating the nutritional differences between different tiers of $\mathrm{OB}$ and MB products.

Key words: market brand; own brand; private label; healthiness; promotions; FOP labelling 


\section{Introduction}

Demand for own brand (OB) (otherwise known as private label) products (products that retailers put their own names or brands on, otherwise known as private label, own-label, retailer brands, store brands, and house brands) has increased significantly worldwide (Loureiro, 2017; Sansone et al., 2020). Financial pressure during and following the 2008 global financial crisis increased consumer willingness to make changes in their spending habits, with many foregoing market brand products for equivalent OB options (Griffith et al., 2016; Valaskova et al., 2018). Despite economic recovery, adaptations in consumer shopping behaviour have remained, contributing to the ongoing demand for OB products (Gazquez-Abad et al., 2017; Nielson, 2018). Rising food production costs, coupled with financial uncertainty, food supply and pricing issues related to Brexit and the COVID-19 pandemic (Seferidi et al., 2019; ILO, 2020) has potential to impact upon consumers' ability to afford their usual food purchases, thereby potentially increasing willingness to choose more affordable OB options. It therefore appears likely that consumer demand for OB goods will continue, thereby maintaining and increasing the OB grocery market share. Aside from consumer concerns about food affordability, the growth in the OB sector is being driven by the growth of the discounters, as consumers show preference for their everyday low pricing model, as well as increased investment in private label lines to align product offerings with consumer trends and demand (Mintel, 2019). OB products no longer simply serve as a cheaper imitation option but are now at the leading edge in terms of meeting consumer demands for new food products, and have been repositioned from being cheaper imitations of market brands (MBs) to being credible brands in their own right (Huang and Huddleston, 2009; Nielson, 2018). Retailers have successfully built equity into their OB products by investing substantially in product development, extending product lines and increasing marketing activity (Bold, 2014; Castelo et al., 2016; Nielson, 2018). Consequently, OBs have achieved an objective quality similar to that of MBs and at a competitive price (Rubio et al., 2014); however, little is known about the extent of retailers' investment into the nutritional quality of the products. In addition, government attention within the food retailing environment has highlighted concerns relating to the nutritional quality of foods on promotional offer, and it has been recommended that retailers respond by "reducing the point of sale placement of foods which are high in fat, salt, sugar (HFSS) and increasing 
exposure to promotion of healthier foods" (Department of Health, Social Services and Public Safety, 2015, p.73). Therefore, the aim of the present study is to compare retailer's use of sales promotions to market MBs and OBs to consumers, and the comparative nutritional quality of both categories.

\section{Literature review}

MBs include international and national well-known brands, and less well-known regional brands. International and national brands refer to those which are found in many countries around the world, while regional brands refer to those generally available in one country or a narrow geographical area (Winit et al., 2014). OBs have a variety of price and branding strategies which appeal to different consumer segments, with tiered product portfolios often used, rather than a single standard OB range (Lessassy, 2019; Rubio et al., 2019). Value ranges follow an economy strategy, avoiding expensive ingredients and packaging (e.g. Tesco Everyday Value). Mid-market OBs are of better quality than value OBs but are still less expensive than MBs. Premium OBs offer the same or higher quality than MBs (e.g. Tesco Finest) (terBraak et al., 2014; Mintel, 2015; Rossi et al., 2015; Lessassy, 2019). Venture brands are also increasingly being used; these are OBs which do not openly display the retailer's name on the packaging, therefore the consumer is often unaware they are purchasing an OB rather than a MB (Keynote, 2015). Retailers are now taking a more active role in developing and promoting their $\mathrm{OBs}$, rather than passively distributing $\mathrm{MBs}$, with $\mathrm{OB}$ ranges being used to communicate the personality of the store and to differentiate them from competitors (Huang and Huddleston, 2009; Mason, 2018). OB ranges exist across all categories of retailers from the large multi-nationals, medium and small sized convenience stores, and discounters, and OB products exist across virtually all product categories, with OB share being particularly high in certain categories such as fresh and chilled produce (Mason, 2018).

This study examines how retailers use sales promotions to increase awareness of MBs and OBs, and is underpinned by the theory of brand equity (Aaker, 1991), which premises that various assets linked to a brand (brand loyalty, brand awareness, perceived quality, brand associations, other proprietary brand assets) will affect how consumers perceive and respond to the products offered by the brand (Sasmita and Suki, 2015; Datta et al., 2017). Brand equity is obtained in part through brand identification - i.e. consumers familiarity with and awareness of brands (Datta et al., 2017). In-store sales promotions are one method whereby retailers can improve brand identification, and thereby can raise the brand equity of a product (Sinha and 
Verma, 2018). Sales promotions are not only effective tools for increasing sales but can be used to develop relationships with customers, enhancing consumers attitudes and loyalty towards a brand (Palazón-Vidal and Delgado-Ballester, 2005; Mussol et al., 2019). This paper focuses on retailer's sales promotion of MBs and OBs, therefore specifically considers the 'brand awareness' element of Aaker's (1991) conceptual model, i.e. retailer's use of sales promotions to increase consumer awareness of $\mathrm{MBs}$ and $\mathrm{OBs}$, and how this subsequently impacts on brand equity. Retailer marketers know that offering promotions on popular MBs will attract customers' attention and can be used as a tool for competitive advantage, encouraging consumers to shop in their store over another. It is assumed that retailers will more often use sales promotion strategies on MB rather than $\mathrm{OB}$ products, as MBs on promotion are more likely to appeal to deal-prone consumers than OBs on promotion, as they represent greater value (Sethuraman and Gielens, 2014). Sales promotions on leading MB products can therefore be used as a tactical strategy to entice consumers to a particular store where they will often buy additional items, thus increasing sales and subsequent profit (Powell et al., 2016). Further, retailers' OBs generally have a relatively low initial reference price point (Rubio et al., 2014; Collins et al., 2015) due to low marketing expenditures and supply prices (Baltas and Argouslidis, 2007) therefore promotions on OB products, especially those in the value tier, are often not financially viable as they would not produce adequate return to make them justifiable. In addition to this, further lowering the price of value brands could have a detrimental impact on how consumers perceive their quality (Ashworth et al., 2005), thereby affecting brand equity (Aaker, 1991). It is therefore expected that:

H1. MB food products will be more frequently promoted than OB food products.

Consumers often associate sales promotions with less healthy products (McKeown, 2013; Samoggia et al., 2019), and the literature also suggests that sales promotions are applied to less healthy foods (Bennett et al., 2020). For example, retail audit studies conducted in various supermarkets across regions in the Netherlands (Ravensbergen et al., 2015), the US (Powell et al., 2016), and Australia (Riesenberg et al., 2019) commonly concluded that less healthy product varieties were more frequently promoted than healthier varieties. In the UK however, Nakamura et al. 's (2015) analysis of a secondary panel data source which included records of food and drink products $(n=11,323)$ purchased by UK households $(n=26,986)$ indicated that less healthy products were no more frequently promoted than healthier products, but that there was a greater uptake by consumers of products on promotion in less healthy categories than in healthier categories. 
Retailers, and their use of marketing techniques such as sales promotions, play a key role in promoting and guiding certain food consumption behaviours, such as that of more healthful eating (Samoggia et al., 2019; Grandi et al., 2020). Sales promotions can alter consumer's regular buying behaviour, encouraging them to stockpile, brand switch, or make unplanned purchases (Chandon and Wansink, 2012; Nakamura et al., 2015; Powell et al., 2016). This can be a problematic practice when the products concerned are high in fat, salt and sugar, and when larger promotional sizes of less healthy foods are promoted, as frequent promotion of these foods may habituate consumers towards buying and consuming them regularly and in larger portions, encouraging unhealthy dietary behaviour (Powell et al., 2016). It has been well established that diet plays an influential role in the risk of developing obesity and noncommunicable diseases, such as diabetes and coronary heart disease (Knai et al., 2015). Therefore, frequent promotion of less healthy foods, leading to frequent purchase and consumption, may result in development of dietary related health problems (Powell et al., 2016; Riesenberg et al., 2019). It is inevitable that foods high in fat, salt and sugar will always exist in the marketplace to meet consumer demand, however promotional activity surrounding these foods makes them even more affordable, and further increases their visibility. Retailers are therefore continuing to be encouraged by the government to reduce promotion of foods which are high in fat, salt and sugar (DHHSP, 2015), and this study uses a dataset of foods on promotion to investigate retailers' compliance with these recommendations. According with general consumer opinion and previous research findings, this study hypothesises that:

H2. There will be more less healthy foods on promotional offer than healthy foods.

The lower cost of $\mathrm{OB}$ foods has been attributed to the use of cheaper ingredients and reduced spend on packaging and advertising, and often consumers perceive OB ranges to be nutritionally inferior to MB equivalents (Bold, 2014). Although the stigma that OB products are of poor quality is increasingly being overcome (Loebnitz et al., 2020), considering the willingness of many consumers to trade down from $\mathrm{MB}$ to $\mathrm{OB}$, there is scope for retailers to further drive marketing around their $\mathrm{OB}$ ranges to further increase consumer acceptability and willingness to choose OBs over MBs. Additionally, it is likely that there are many, particularly those in lower socioeconomic groups who spend disproportionately more on their food budgets than their higher income counterparts, and whose primary priority when purchasing food is keeping price to a minimum (McKeown, 2013; King et al., 2015). For these consumers in particular, promotions and value ranges will appeal, and therefore identifying whether OB ranges on promotion have a similar nutrient profile to MBs on promotion can help assess the 
nutritional adequacy of a diet containing in the majority OB foods. To date, findings from studies examining the nutritional profile of MBs versus OBs vary, with some indicating that OB products have a nutritional composition similar to, or better than MB equivalents (Cooper and Nelson, 2003), others that there is no significant difference in overall nutritional quality between MBs and OBs (Faulkner et al., 2014), and others that MB products are slightly healthier than OB products (Lappi et al. (2020). However, existing research on this topic is limited, is based on small sample sizes and does not focus specifically on promotional data. Therefore, the present study will be unique in analysing the nutritional quality of MBs and OBs using a large dataset of foods on promotional offer which is representative of retailers across Northern Ireland (NI). In addition, no research to date has been identified investigating the nutritional differences between different tiers of $\mathrm{OB}$ and MB products. It is hypothesised that:

H3. OB food products on promotional offer will be less healthy than MB products.

Investigating retail food promotions among $\mathrm{OBs}$ and $\mathrm{MBs}$ can inform marketing recommendations for manufacturers and retailers to build brand equity, further engage consumers and increase sales across both sectors.

\section{Methods}

A quantitative secondary data analysis approach was employed for this study. Ethical approval was granted by [anonymised for review] Ethics Filter Committee. Confidentiality of retailers is important therefore no retailers name is used throughout.

\section{Data}

An existing audit tool designed by researchers from [anonymised for review] upon commission from the Food Standards Agency (FSA) in Northern Ireland (NI) and the Consumer Council in NI (CCNI) was used as the sample for this study. The tool consists of information on a range of food items on promotion $(n=6776)$ from forty-eight stores (24 of which were supermarkets/discounters and 24 were convenience stores) across eight retail chains in Northern Ireland (NI) including Tesco, Asda, Marks and Spencer, Lidl, The Henderson Group, Musgrave, Nisa and The Cooperative. All chains involved within this study carry OB except for Nisa that carries The Cooperative OBs (The Cooperative acquired Nisa in 2018). Data was collected during two phase periods between October 2014 and February 2015. This database 
was selected for use as an appropriate sample to use to investigate the research questions due to its large sample size $(n=6,776)$, its representativeness of a variety of food products and retailers, and as it provided a relevant healthiness score and category for each product. The healthiness scores accorded with the FSA front of pack (FOP) nutrient labelling methodology (FSA, 2013), and products were allocated to the appropriate FOP healthiness category as follows: $\operatorname{Red}=<8$ (low healthiness score); Amber $=9-12$ (medium healthiness score); and Green $=13-15$ (high healthiness score). As amber products are neither high nor low in the specific nutrient it is recommended that you can eat these foods all or most of the time so consumers are encouraged to opt for more greens and ambers when making choices (Department of Health, 2016). Therefore, both amber and green categories were combined for analysis to indicate products of high-medium healthiness. For further details on calculation of scores and categories, see Hollywood et al. (2016).

\section{Secondary Analysis}

Food items were recoded into two categories, either $\mathrm{MB}$ or $\mathrm{OB}$, then $\mathrm{MB}$ products were further recoded depending on whether they are international, national or regional (local) brands, and OBs recoded according to premium, mid-market and value ranges (Table I). Following recoding into relevant $\mathrm{MB}$ or $\mathrm{OB}$ categories, descriptive statistics were analysed to ascertain frequencies of products within each product category and to compare how healthiness scores of products vary between MB and OB subsets. Chi-square $\left(X^{2}\right)$ tests of independence (and related degrees of freedom) were used to examine the statistical significance of the results (i.e. to examine whether there is a significant association between the independent and dependent variables, or whether they are independent of each other). Applying a $X^{2}$ and crosstabulation analytic approach was deemed appropriate based on similar previous research (Jahns et al. 2014; Fagerberg, et al. 2019). $X^{2}$ values with a 95\% confidence level $(p<0.05)$ were deemed significant. Cramer's V was used to calculate effect sizes to further indicate the strength of association of the relationship between the independent and dependent variables. Effect sizes were interpreted as small, medium or large related to degrees of freedom in accordance with widely accepted recommendations by Cohen (1988), who identified that a value of 0.1 is considered a small effect size (accounting for $1 \%$ of the total variance), 0.3 is a medium effect size (accounting for $9 \%$ of the total variance) and 0.5 or above is a large effect size (accounting for $25 \%$ of the total variance) (Field, 2017). The greater the effect size the greater the difference in relationship between the two tested variables (Sullivan and Feinn, 2012). 


\section{INSERT TABLE I HERE}

\section{Results}

Results across the dataset $(n=6776)$ relating to the proportion of MB products versus OB products on promotion are firstly presented, followed by findings relating to the healthiness of $\mathrm{MB}$ and $\mathrm{OB}$ products (and their respective sub-sets) according to FOP category.

\section{Proportion of market brands and own brands on promotion}

Results reported that a higher proportion of the products on promotion were MB ( $\mathrm{n}=5019$, $74.1 \%)$, as opposed to $\mathrm{OB}(\mathrm{n}=1757,25.9 \%)$ (Table II). Within the MB category, results revealed that the majority of products on promotion $(88.5 \%)$ were national/international brands, while only $11.5 \%$ of the MBs studied were regional brands. The greatest proportion of OBs on promotion were mid-market $(\mathrm{n}=1668,94.9 \%)$.

\section{INSERT TABLE II HERE}

\section{Healthiness of products on promotion}

The red category was the single category with the greatest number of products $(n=3225$, $47.6 \%)$, followed by those in the amber category $(n=2201,32.5 \%)$, as seen in Table III. Collectively there was a slightly greater percentage of healthier (green-amber) products on promotion $(\mathrm{n}=3551,52.4 \%)$. These findings were significant, but associated effect size was relatively small $\left(\chi^{2}(1)=158.37, p<0.001\right.$, Cramer's V $\left.=0.15\right)$, indicating that although there is a significant relationship between these variables, the strength of relationship is fairly weak.

\section{INSERT TABLE III HERE}

\section{Total FOP category - Market Brands}

Slightly more products in the MB category were categorised as less healthy, with over half of the products in the MB sample ( $\mathrm{n}=2616,52.1 \%$ ) being in the red FOP category, followed by 
$29.8 \%(n=1495)$ in the amber FOP category. These findings were significant but with a small effect size $\left(\chi^{2}(1)=24.95, \mathrm{p}<0.001\right.$, Cramer's $\left.\mathrm{V}=0.07\right)$.

\section{Total FOP category - Own Brands}

Of the OB sample, $40.2 \%(n=706)$ of products were in the amber FOP category, followed by $34.7 \%(n=609)$ in the red category. Therefore, collectively a greater percentage of products had a high-medium FOP healthiness score (green-amber) $(n=1148,65.3 \%)$ than a low FOP healthiness score (red). These findings were significant $\left(\chi^{2}(2)=16.75, \mathrm{p}<0.001\right.$, Cramer's $\mathrm{V}=$ 0.98), with a large effect size, indicating meaningful difference between the groups.

\section{Total FOP healthiness category - MB and OB comparison}

The MB sample had more products $(n=2616,52.1 \%)$ in the red FOP category compared to the OB sample $(n=609,34.7 \%)$. The OB sample had a greater proportion of products in the amber FOP category $(n=706,40.2 \%)$ than the MB sample $(n=1495,29.8 \%)$. The OB sample had more products in the green FOP category $(n=442,25.1 \%)$ than the MB sample $(n=908,18.1 \%)$. Collectively, the OB sample had a greater percentage of high-medium FOP score products $(n=1148,65.3 \%)$ than the MB sample $(n=2403,47.9 \%)$, indicating that overall, the OBs on promotion were healthier than MBs on promotion. A chi-square test of independence found a significant difference in MB and OB FOP categories with a small/medium effect size $\left(\chi^{2}=\right.$ 159.3 (2), $\mathrm{p}<0.001$, Cramer's $V=0.15$ ). These results suggest that the OB sample was healthier than the MB sample, having both a significantly greater percentage of products in the highmedium (green-amber) FOP category, and a significantly lower percentage of products in the red category.

\section{FOP category of MBs - National/International and Regional sub-categories}

Within the national/international MB category, just over half of products $(50.9 \%)$ were in the red FOP category, followed by $29.9 \%$ in the amber FOP category (Table IV). Collectively, products with high-medium FOP score (green-amber) $(n=2184,49.1 \%)$ were almost equal in the sample to products with low FOP score (red) $(n=2260,50.9 \%)$.

Within the regional MB category, the majority of products were in the red FOP category $(n=356,61.9 \%)$, followed by $29 \%$ of products in the amber FOP category. Collectively, 
products with high-medium FOP score (green-amber) $(n=216,38 \%)$ were in the minority compared to products with a low FOP score (red).

\section{INSERT TABLE IV HERE}

FOP healthiness category of MBs - National / International and Regional sub-category comparison

Overall, the regional MB sample contained more products with red FOP labelling $(n=356$, $61.9 \%)$ than the national/international MB sample $(n=2260,50.9 \%)$. The percentage of products within the amber FOP category was almost identical in both the international/national and regional MB samples (29.9\% and 29.0\% respectively). The international/national MB sample had more products categorised as green $(n=856,19.3 \%)$ than the regional sample $(n=52$, $9 \%)$, and also more products categorised as green-amber $(n=2184,49.1 \%)$ than the regional sample $(n=216,38 \%)$. Chi-square test of independence report significant differences between FOP categories of international/national and regional MBs, with a small-medium effect size $\left(\chi^{2}=159.3\right.$ (2), $\mathrm{p}<0.001$, Cramer's $\left.\mathrm{V}=0.153\right)$. Overall, results suggest that the international/national MBs in this sample were healthier than the sampled regional MBs, as international/national MBs had fewer products in the red FOP category, and more products in the green and green-amber FOP categories.

FOP healthiness category of OBs - Premium, mid-market and value sub-categories

Over half ( $\mathrm{n}=40,51.9 \%$ ) of OB premium tier products had a low FOP score (red), followed by $36.4 \%$ ( $n=28)$ with medium FOP score (amber). Collectively, there were only slightly more products with a low FOP score (red) $(n=40,51.9 \%)$ than there were products with a highmedium FOP score (green-amber) $(n=37,48.1 \%)$. The greatest percentage of mid-market OBs were in the amber category $(n=677,40.6 \%)$, followed by those in the red category $(n=569$, $34.1 \%)$. A larger percentage $(n=1099,65.9 \%)$ had collectively high-medium FOP scores (green-amber).

The majority of value tier products $(\mathrm{n}=11,91.7 \%)$ had a high FOP score (green category) and the remainder ( $\mathrm{n}=1,8.3 \%$ ) were in the amber category. However, the value tier sample is not robust enough to garner conclusions that are representative of value OBs as the sample size of 
value label $\mathrm{OB}$ products was extremely small $(n=12)$, comprising just $0.2 \%$ of the entire promotional dataset.

FOP healthiness category of $O B$ - Premium, mid-market and value sub-category comparison

Premium OBs had the greatest proportion of products in the red FOP category $(n=40,51.9 \%)$, followed by mid-market ( $\mathrm{n}=28,36.4 \%$ ). The value OB sample contained no products in the red FOP category. Mid-market OBs had the greatest proportion of products in the amber FOP category $(n=677,40.6)$, followed by premium OBs $(n=28,36.4 \%)$. The largest proportion of products in the green FOP category was found in the value OB tier $(n=11,91.7 \%)$, followed by mid-market $(\mathrm{n}=422,25.3 \%)$. As the value OB sample contained no products in the red FOP category, $100 \%$ of value OB products had a high-medium FOP score (green-amber), followed by the mid-market tier $(n=1099,65.9 \%)$ and the premium OB tier $(n=2403,47.9 \%)$. Overall, within the present sample value tier OB products were the healthiest, and premium label OB products the least healthy. Although these results were statistically significant $\left(\chi^{2}=41.9\right.$ (4), $\mathrm{p}<0.001$, Cramer's $\mathrm{V}=0.154$ ) they cannot be considered meaningful as an assumption of the $\chi^{2}$ test was violated in that three cells had expected count less than five (Green and Salkind, 2012).

\section{Discussion}

Findings will hereafter be discussed in relation to each proposed hypothesis, followed by practical recommendations.

\section{Proportion of $M B$ versus $O B$ products on promotion (H1)}

The finding that almost three-quarters of the products on promotion were MB rather than OB is as expected, and is logical considering that MBs on promotion offer greater value for consumers than OBs on promotion (Sethuraman and Gielens, 2014), and considering the comparative financial viability of promoting both categories (Rubio et al., 2014). The majority of MBs in the study sample were categorised as international/national. It is assumed that this can be explained by the fact that there are inevitably a smaller number of regional brands available in stores. However, in addition to this it is assumed that retailers choose to promote international/national brands more frequently as they are often more readily recognised and 
desired by consumers (Rossi et al., 2015), therefore they stand to have a greater sales volume and thus profit over the promotional period (Powell et al., 2016). Despite the acknowledged positive effect of OB brand equity on store loyalty (Rubio et al., 2019), it is likely that the current study's finding regarding more frequent promotion of MBs in relation to OBs, is the result of a strategic decision taken by retailers, in recognition that the brand equity of MBs in relation to their perceived value, brand awareness, perceived quality and brand associations, is often greater than that of $\mathrm{OBs}$, and therefore $\mathrm{MBs}$ on promotion are likely to be more attractive to consumers, and more profitable for retailers.

It is quite surprising that the tier which retailers presumably invest most money into (premium) (Rossi et al., 2015) is not more widely promoted, as research has found that consumers trust OB premium ranges, and associate them with high quality (Wells et al., 2007; Loebnitz et al., 2020), therefore increasing premium OB visibility using promotions could be a useful strategy to increase sales and build consumers' positive associations towards these products (Powell et al., 2016). However, sales promotions may negatively affect consumers perceptions of a premium product brand (Zoellner and Schaefers, 2015), perhaps explaining retailers' apparent decision to minimise the number of premium OB products on promotion. Further, the sample contained a smaller number of premium $\mathrm{OB}$ products relative to mid-market $\mathrm{OB}$ range products, therefore the lack of premium OB products on promotion is perhaps more reflective of retail stores having smaller premium OB ranges in comparison with mid-market ranges, than it is retailers choosing not to promote them. Considering the aforementioned small margin of profit potential with value ranges, it is understandable why such a small amount of OB value products were on promotion.

\section{Healthiness (front of pack (FOP) category) of products on promotion (H2)}

Over half of the promotional sample had a green-amber FOP score, therefore overall there was a balance of health $(52.4 \%$ amber/green versus $47.6 \%$ red) across retailer's promotions. Therefore despite sales promotions often being attributed with responsibility for expanding expenditure on calorie-rich processed foods, conversely the results of this study show they have also been used to promote, and thus encourage consumption of, healthy foods such as fruit and vegetables. Although there was a balance of health using the amber/green versus red 
categorisation, it is acknowledged that when FOP categories were examined singularly, foods with a low FOP score (red category) had the greatest category frequency of promotions. Therefore, depending on how healthiness is categorised, results both agree and disagree with previous study conclusions that less healthy foods are promoted more widely than healthy foods (Ravensbergen et al., 2015; Powell et al., 2016; Riesenberg et al., 2019; Samoggia et al., 2019). It is also possible that study setting and corresponding regulations or government recommendations regarding promotions of (less healthy) foods could be an impacting factor on differing study results. As previously discussed, a study using a secondary panel dataset of UK consumers grocery purchases indicated that more products on promotion were in healthier product categories than less healthy product categories (Nakamura et al., 2015), whereas the previous studies cited which found that less healthy foods were promoted more widely than healthy foods, were conducted in the Netherlands (Ravensbergen et al., 2015), the USA (Powell et al., 2016), and in Australia (Riesenberg et al., 2019). Typically healthy products such as fresh fruit and vegetables make up a smaller proportion of a retail store, and packaged foods are more likely to have a high FOP score as many food manufacturers add fats and oils, sugars and salt to foods to increase flavour, and to improve texture and shelf life (Lv et al., 2011). In addition to this, there are fewer 'branded' healthy products on the marketplace, as fruit and vegetables are often viewed as commodity items (Jha, 2014). These factors may explain the deficiency of products on promotion in this study with a green FOP score, and the common perception that less healthy foods are in the majority promoted.

\section{Healthiness (front of pack category) of $M B$ versus $O B$ products on promotion (H3)}

Analysis of the FOP categories of both MBs and OBs in the sample shows that overall, OB products were healthier than MB products. This is interesting considering previous study findings regarding consumers attitudes to OBs versus MBs which found that $58 \%$ of consumers consider MBs to be of superior overall quality to OBs (Bold, 2014). The results from this study however provide evidence that OB products, are on the contrary, often nutritionally superior to MBs. This statement correlates with certain previous study findings (Cooper and Nelson, 2003; Faulkner et al., 2014) that OB products have a nutritional composition similar to, or better than MB equivalents. From a public health perspective, this finding provides evidence that consumers with reduced disposable income can nonetheless acquire a nutritionally adequate diet. From a marketing perspective, this finding creates opportunity for retailers to promote 
product characteristics (nutritional profile) of OBs as well as price for competitive advantage and to increase overall brand equity.

It is significant that the international/national brands in the promotional dataset were healthier than the regional brands, as marketing activity frequently surrounds local products, and consumers are increasingly choosing to buy local (Charton-Vachet et al., 2020), perceiving local products to be safer, better quality, or because they want to support their local economy (Giampietri and Finco, 2016; Charton-Vachet et al., 2020). Therefore, considering consumers' increasing demand for health, where relevant, regional producers could further improve brand equity by addressing their products' nutritional profile to compete effectively with dominant MBs. However, it is possible that consumers will accept regional products regardless of nutritional quality as they may believe other attributes outweigh their apparent nutritional downfalls, and producers should be aware that alterations to the nutritional profile of products could adversely affect consumers brand associations if the flavour of the products is significantly altered.

Considering the MB sample as a whole, the finding that over half of the products in both the international/national and regional categories had a red FOP score is a cause for concern if these products are consumed frequently. FOP labels act as a means of communicating nutritional information about a product to consumers, therefore the option of including voluntary FOP labels on their products may be an incentive for producers to reformulate and develop healthier products to increase consumer acceptance (Lehmann et al., 2017; Samoggia et al., 2019), in order to compete in an increasingly health conscious marketplace (Hanspal and Devasagayam, 2017). In addition, transparency regarding the nutritional profile of products could increase consumer perceptions of a brand, and therefore increase brand equity. The finding that regional MBs are less healthy than international/national MBs provides scope for SMEs in NI to improve the nutritional status of their products to provide them with increased competitive advantage against international/national MBs.

Considering the present OB sample, premium OBs are the least healthy OB tier. It can be assumed this is because these higher-value products often contain more complex ingredients than other OB tiers, or ingredients high in fat, salt and sugar to add flavour, in order to compete 
with MBs. Research indicates that premium OBs have been successful in competing with MBs; consumers associate premium OBs with being high quality and trustworthy (Wells et al., 2007; Loebnitz et al., 2020), and despite their higher costs relative to other OBs, are still perceived by consumers to be better value than MBs (Nenycz-Thiel and Romaniuk, 2016). Wells et al (2007) found that consumers' buying behaviour towards premium OB products was often highly driven by emotions - with consumers rewarding themselves after a good day, and comfort eating after a bad day. In light of both this emphasis on premium OB products as 'treat' products, and of competition from MBs, it is perhaps therefore understandable why premium OBs are so high in fat, salt and sugar, as they are formulated as such to meet consumers demands for quality and taste, and to prolong shelf life (Lv et al., 2011; Rossi et al., 2015). Although the OB promotional sample was representative in indicating that premium OB products are less frequently promoted, it is not significant in indicating the nutritional quality of premium OB products as a whole, as the premium OB sample was too small to make accurate comparisons, therefore frequent inclusion of premium OB products in consumers diets' is not necessarily an unhealthy practice. The present mid-market OB sample has a reasonably good nutritional profile, and is thought to be representative as mid-market products composed the majority of the $\mathrm{OB}$ sample. The value $\mathrm{OB}$ tier was the healthiest subset of products on promotion in the entire sample, however, a conclusion cannot be made that value OBs are nutritionally superior to other OB tiers and MBs, based on this small sample size.

\section{Practical implications}

Findings contradict typical consumer perceptions that price is positively associated with nutritional quality (Gazquez-Abad and Martinez-Lopez, 2016) as not only were OB products healthier than MB products, but in addition to this, standard and value OB tiers were healthier than premium $\mathrm{OB}$ tier. OB use is often associated with lower quality consciousness; however, these findings provide proof that, in terms of nutritional quality, OBs are not inferior. Therefore, retailers could consider communicating the comparative healthiness of their OB products in comparison to MB alternatives, in addition to communicating comparative price savings. The lower sample numbers of OBs on promotion relative to MBs rationalise that there is opportunity at both the mid-market and premium OB levels to increase promotion and visibility. Given that many consumers are keen to trade down from MBs to save money, yet may have a lingering perception of OBs as being of lesser quality, placing more OB products 
on promotion will have a dual effect of firstly making them more visible to the consumer, and secondly, the lower promotional price will remove some of the risk of purchasing (Loebnitz et $a l ., 2020)$. It is recognised that the greater brand equity of MBs in relation to OBs justifies the decision to include more MBs on promotion, however, Aaker (1991) theorises that brand awareness is an important element of brand equity, therefore increasing the visibility of OBs using promotions could help to increase overall $\mathrm{OB}$ brand equity. However, although salespromotions are the most likely marketing factor to prompt shoppers to purchase a new food product (Soininen, 2015), OB sales promotions should be carefully considered in terms of brand image, as price promotions have indirect effects on consumers' internal evaluation of the appropriate price for, and value of a product, thereby influencing brand equity and future demand (Lin, 2016). Therefore, in addition to, or instead of, sales promotions, non-price marketing tactics such as advertising and sampling should also be considered to promote OB products (Sethuraman and Gielens, 2014). Retailers may find this particularly useful for promoting OB products that consumers are unaccustomed to, as research has found that using product sampling significantly increases consumers' perception of OB products (Diallo et al., 2013). Study findings provide rationale for further research to investigate like-by-like nutritional comparisons of $\mathrm{OB}$ and $\mathrm{MB}$ product types, and further consumer research regarding important attributes of OBs,i.e. is healthiness of regional products of importance, thereby justifying reformulation of products in this category (related to the finding that this category had the highest proportion of 'red' products), or how important to consumers is the healthiness of OBs overall. Further, the study provides an overview of methods which can be replicated in other similar studies, internationally or locally.

\section{Limitations}

It is acknowledged that certain limitations in this study exist. As this dataset focused exclusively on products on promotion, there was an inequality in the number of $\mathrm{MB}$ and $\mathrm{OB}$ products included, and in particular there were a lack of $O B$ value products. As value ranges exist at a minimum price point, it is infrequent that these products would be on promotion hence their disparity in the dataset. The data collection was limited to retail stores in Northern Ireland, however as the retail sample included multinational retailers, the findings have assumed applicability to other regions of the UK. 


\section{Conclusion}

This study analysed a large sample of products on promotion $(n=6776)$ to determine the proportionality of promotions around MBs versus OBs, and to investigate the comparable healthiness of $\mathrm{MB}$ and $\mathrm{OB}$ products on promotion. Findings show that there is a balance in favour of health $(52.4 \%$ amber/green vs. $47.6 \%$ red) across retailer's promotions in NI. Additionally, results show that OB products are often superior to MBs with regards to nutrient status. This finding creates opportunity for retailers to increase brand equity by promoting the favourable product characteristics (nutritional profile) of OBs versus MB alternatives, in addition to promoting price comparisons. Regional MBs were less healthy than international/national MBs, therefore improving the nutritional profile of regional MBs may increase competitive advantage and brand equity, depending on whether, or to what extent, nutritional content (healthiness) is an important attribute for consumers when choosing premium OBs. Consumer research can further examine consumer preferences regarding attributes of $\mathrm{OBs}$, and regarding factors impacting on $\mathrm{OB}$ brand equity. These results can inform retailers marketing and managerial strategies regarding increasing visibility of $\mathrm{OB}$ products and promoting OB product healthiness via sales promotions to improve brand equity.

\section{References}

Aaker, D.A. (1991), Managing brand equity: capitalizing on the value of a brand name, The Free Press, New York, NY.

Ashworth, L., Darke, P.R. and Schaller, M. (2005), "No one wants to look cheap: trade-offs between social disincentives and the economic and psychological incentives to redeem coupons", Journal of Consumer Psychology, Vol.15 No.4, pp.295-306.

Baltas, G. and Argouslidis, P.C. (2007), "Consumer characteristics and demand for store brands", International Journal of Retail \& Distribution Management, Vol.35 No.5, pp.328341.

Bennett., R, Zorbas., C, Huse., O, Peeters, A., Cameron, A.J., Sacks, G. and Backholer, K. (2020), "Prevalence of healthy and unhealthy food and beverage price promotions and their potential influence on shopper purchasing behaviour: A systematic review of the literature", Obesity Review, Vol.21 No.1, e12948. 
Bold, B. (2014), "Supermarket own-brands generate more than half of UK grocery sales", available at: http://www.marketingmagazine.co.uk/article/1324180/supermarket-own-brandsgenerate-half-uk-grocery-sales (accessed 11 March 2021).

Castelo, J.S.F., de Oliveira Cabral, J.E. and Coelho, A.F.M. (2016), "Comparative analysis of the antecedents and dimensions of brand equity between food processors' brands and supermarket's private labels", Brazilian Business Review, Vol.13 No.1, pp.69-91.

Charton-Vachet, F., Lombart, C. and Louis, D. (2020), "Impact of attitude towards a region on purchase intention of regional products: the mediating effects of perceived value and preference", International Journal of Retail \& Distribution Management, Vol.48 No.7, pp. 707-725.

Chandon, P. and Wansink, B. (2012), "Does food marketing need to make us fat? A review and solutions", Nutrition Reviews, Vol.70 No.10, pp.571-593.

Cohen, J. (1988), “Statistical power analysis for the behavioural sciences”, $2^{\text {nd }}$ ed, Lawrence Erlbaum Associates, Hillsdale, NJ.

Collins, A.M., Cronin, J.M., Burt, S. and George, R.J. (2015), "From store brands to store brandscapes: the emergence of a time and money saving heuristic", European Journal of Marketing, Vol.49 No.5/6, pp.894-918.

Cooper, S. and Nelson, M. (2003), "Economy line foods from four supermarkets and brand name equivalents: a comparison of their nutrient contents and costs", Journal of Human Nutrition and Dietetics, Vol.16 No.5, pp.339-347.

Datta, H., Ailawadi, K., and Van Heerde, H. (2017), "How well does consumer-based brand equity align with sales-based brand equity and marketing-mix response?" Journal of Marketing, Vol.81 No.3, pp.1-20.

Department of Health (2016). "Guide to creating a front of pack (FoP) nutrition label for prepacked products sold through retail outlets", available at: https://www.food.gov.uk/sites/default/files/media/document/fop-guidance 0.pdf (accessed 23 July 2021).

Department of Health, Social Services and Public Safety (2015), "A fitter future for all: outcome framework 2015-2019”. available at: https://www.health- 
ni.gov.uk/sites/default/files/publications/dhssps/fitter-future-for-all-outcomes-framework-

2015-2019.pdf (accessed 11 March 2021).

Diallo, M.F., Chandon, J.L., Cliquet, G. and Philippe, J. (2013), "Factors influencing consumer behaviour towards store brands: evidence from the French market", International Journal of Retail \& Distribution Management, Vol. 41 No.6, pp.422-441.

Fagerberg, P., Langlet, B., Oravsky, A., Sandborg, J., Löf, M., and Ioakimidis, I. (2019), "Ultra-processed food advertisements dominate the food advertising landscape in two Stockholm areas with low vs high socioeconomic status. Is it time for regulatory action?", $B M C$ Public Health, Vol.19 No.1, pp.1717.

Faulkner, G.P., Livingstone, M.B.E., McCaffrey, T.A. and Kerr, T.A. (2013), "Supermarket own brand foods: lower in energy cost but similar in nutritional quality to their market brand alternatives", Journal of Human Nutrition and Dietetics, Vol.27, pp.617-625.

Food Standards Agency (2013), "Guide to creating a front of pack (FoP) nutrition label for pre-packed products sold through retail outlets", available at: https://www.food.gov.uk/sites/default/files/media/document/fop-guidance 0.pdf (accessed 11 March 2021).

Field, A. (2017), "Discovering statistics using IBM SPSS statistics", $5^{\text {th }}$ ed. London: SAGE.

Gazquez-Abad, J.C. and Martinez-Lopez, F.J. (2016), “Increasing a brand's competitive clout: the role of market share, consumer preference, and price sensitivity", Journal of Marketing Management, Vol.32 No.1-2, pp.71-99.

Gazquez-Abad, J.C., Martinez-Lopez, F.J. and Esteban-Millat, I. (2017), "The role of consumers'attitude towards economic climate in their reaction to 'PL-only' assortments: evidence from the United States and Spain", Journal of Retailing and Consumer Services, Vol.34, pp.340-348.

Giampietri, E., Finco, A. and Giudice, T.D. (2016), “Exploring consumers' behaviour towards short food supply chains", British Food Journal, Vol.118 No.3, pp.618 - 631.

Grandi, B., Cardinali, M.G. and Bellini, S. (2020), "Health and self-control: promoting unconscious healthy food choices inside the store", International Journal of Retail \& Distribution Management, Vol.48 No.3, pp.229-243. 
Griffith, R., O’Connell, M. and Smith, K. (2016), “Shopping around: how households adjusted food spending over the great recession", Economica,Vol.83, pp.247-280.

Hanspal, S. and Devasagayam, P.R. (2017), "Impact of consumers' self-image and demographics on preference for healthy labelled foods", SAGE Open, Vol.7, No.1, available at: doi:10.1177/2158244016677325 (accessed 11 March 2021).

Hollywood, L., Furey, S., Burns, A., McMahon-Beattie, U., Price, R., Duffy, M., Dowler, E., Livingstone, B., Humphreys, P., Moore, C. and McCullagh, F. (2016), "A three-stage investigation into the balance of healthy versus less healthy food promotions among Northern Ireland food retailers", available at: https://www.food.gov.uk/sites/default/files/media/document/fs305021 fsasummaryreportmarc h16.pdf (accessed 11 March 2021).

Huang, Y. and Huddleston, P. (2009), "Retailer premium own-brands: creating customer loyalty through own-brand products advantage", International Journal of Retail \& Distribution Management, Vol. 37 No. 11, pp. 975-992.

ILO (2020), "Almost 25 million jobs could be lost worldwide as a result of COVID-19", available at: https://www.ilo.org/global/about-the-ilo/newsroom/news/WCMS_738742/lang-en/index.htm (accessed 11 March 2021).

Jahns, L., Payne, C. R., Whigham, L. D., Johnson, L. K., Scheett, A. J., Hoverson, B. S. and Kranz, S. (2014), "Foods advertised in US weekly supermarket sales circulars over one year: a content analysis", Nutrition Journal, Vol.13, pp.95.

Jha, M. (2014), "Effective marketing strategy for branding a commodity with special reference to consumer goods", International Journal of Social Science and Interdisciplinary Research, Vol.3 No.5, pp.120-128.

Keynote (2015), "Supermarket own labels: food and drink”, available at: https://www.keynote.co.uk/market.../supermarket-own-labels-food-drink (accessed 11 March 2021).

King, G., Lee-Woolf, C., Kivinen, E., Hrabovski, G. and Fell, D. (2015), “Understanding food in the context of poverty, economic insecurity and social exclusion", available at: https://www.food.gov.uk/sites/default/files/media/document/FS307008\%20\%20Food\%20Poverty\%20Final\%20Report.pdf (accessed 11 March 2021). 
Knai, C., Petticrew, M., Durand, M.A., Eastmure, E., Mehrotra, A., Scott, C. and Mays, N. (2015), "Has a public-private partnership resulted in action on healthier diets in England?", Food Policy, Vol.54, pp.1-10.

Lappi, V.M., Mottas, A., Sundström, J., Neal, B., Löf, M. and Rådholm, K. (2020), “A comparison of the nutritional qualities of supermarket's own and regular brands of bread in Sweden”, Nutrients, Vol.12, 1162.

Lehmann, U., Charles, V.R., Vlassopoulos, A., Masset, G. and Spieldenner, J. (2017) Nutrient profiling for product reformulation: public health impact and benefits for the consumer. Proceedings of the Nutrition Society, Vol.76. pp.255-264.

Lessassy, L. (2019), "Replacing a delisted brand with premium and standard private labels: the role of brand preference and shopping trip", International Journal of Retail \& Distribution Management, Vol.47 No.10, pp.1057-1073.

Loebnitz., N., Zielke, S. and Grunert, K.G. (2020), "Consumers' brand decision: a matter of social risk", International Journal of Retail \& Distribution Management, Vol.46, No.6, pp.575589.

Loureiro, S.M.C. (2017), "Exploring the attractiveness of manufacturer brands and retailer own-brands in supermarket context", International Journal of Retail \& Distribution Management, Vol. 45 No. 10, pp. 1095-1113.

Lv, J., Chen, Y., Wang, S., Liu, Q., Ren, Y., Karrar, S. and Li, L. (2011), “A survey of nutrition labels and fats, sugars and sodium ingredients in commercial packaged foods in Hangzhou, China", Public Health Reports, Vol.126 No.1, pp.116-122.

McKeown, A. (2013), "Hard to stomach- the impact of rising food costs for Northern Ireland consumers", available at: www.consumercouncil.org.uk/filestore/.../Hard to Stomach1.pdf (accessed 11 March 2021).

Mintel (2015), "Private label food and non-alcoholic drink - UK", available at: https://reports.mintel.com/display/716239/ (accessed 11 March 2021).

Mintel (2019), “Supermarket retailing - brand vs own brand - Ireland - November 2019”, available at: https://academic.mintel.com/display/990968/ (accessed 11 March 2021). 
Mussol, S., Aurier, P. and de Lanauze, G.S. (2019). "Developing in-store brand strategies and relational expression through sales promotions", Journal of Retailing and Consumer Services, Vol.47, pp.241 - 250 .

Nakamura, R., Suhrcke, M., Jebb, S.A., Pechey, R., Almiron-Roig, E., Marteau, T.M. (2015), "Price promotions on healthier compared with less healthy foods: a hierarchical regression analysis of the impact on sales and social patterning of responses to promotions in Great Britain”, American Journal of Clinical Nutrition, Vol.101 No.4, pp.808-816.

Nenycz-Thiel, M. and Romaniuk, J. (2016), "Understanding premium private labels: a consumer categorisation approach", Journal of Retailing and Consumer Services, Vol.29, pp.22-30.

Nielson (2018), “The rise and rise again of private label”, The Nielson Company, New York, NY. available at: https:/www.nielsen.com/wp-content/uploads/sites/3/2019/04/globalprivate-label-report.pdf (accessed 11 March 2021).

Powell, L.M., Kumanyika, S.K., Isgor, Z., Rimkus, L., Zenk, S.N., Chaloupka, F.J. (2016), "Price promotions for food and beverage products in a nationwide sample of food stores", Preventative Medicine, Vol.86 No.1, pp.106-113.

Palazón-Vidal, M. and Delgado-Ballester, E. (2005),“Sales promotions effects on consumerbased brand equity." International Journal of Marketing Research, Vol.47, No.2, pp. 179-204.

Ravensbergen, E.A., Waterlander, W.E., Kroeze, W. and Steenhuis, I.H. (2015), "Healthy or Unhealthy on Sale? A cross-sectional study on the proportion of healthy and unhealthy foods promoted through flyer advertising by supermarkets in the Netherlands", BMC Public Health, Vol. 15, available at: 10.1186/s12889-015-1748-8 (accessed 6 July 2021).

Riesenberg, D., Backholer, K., Zorbas, C., Sacks, G., Paix, A., Marshall, J., Blake, M., Bennett, R., Peeters, A. and Cameron, A. J. (2019), "Price promotions by food category and product healthiness in an Australian supermarket chain, 2017-2018", American Journal of Public Health, Vol.109 No.10, pp.1434-1439.

Rossi, P., Borges, A. and Bakpayev, M. (2015), "Private labels versus national brands: the effects of branding on sensory perceptions and purchase intentions", Journal of Retailing and Consumer Services, Vol.27, pp.74-79. 
Rubio, N., Oubina, J. and Villasenor, N. (2014), "Brand awareness-brand quality inference and consumer's risk perception in store brands of food products", Food Quality and Preference, Vol.32, pp.289-298.

Rubio, N., Villasenor, N. and Yague, M. (2019), "The role of private label tiers and private label naming strategies in the relationship between private label brand equity and store loyalty", The Journal of Product \& Brand Management, Vol.29 No.1, pp.124-138.

Samoggia, A., Bertazzoli, A. and Ruggeri, A. (2019), "Food retailing marketing management: social media communication for healthy food", International Journal of Retail \& Distribution Management, Vol.47 No.9, pp.928-956.

Sansone, M., Musso, F., Colamatteo, A. and Pagnanelli, M.A. (2021), "Factors affecting the purchase of private label food products", British Food Journal, Vol.123 No.3, pp. 1207-1222.

Sasmita, J. and Mohd Suki, N. (2015), "Young consumers' insights on brand equity: Effects of brand association, brand loyalty, brand awareness, and brand image", International Journal of Retail \& Distribution Management, Vol.43 No.3, pp. 276-292.

Seferidi, P., Laverty, A. A., Pearson-Stuttard, J., Bandosz, P., Collins, B., Guzman-Castillo, M., Capewell, S., O'Flaherty, M., and Millett, C. (2019), "Impacts of Brexit on fruit and vegetable intake and cardiovascular disease in England: a modelling study", BMJ open, Vol.9 No.1, available at: http://dx.doi.org/10.1136/bmjopen-2018-026966 (accessed 11 March 2021).

Sethuramen, R. and Gielens, K. (2014), "Determinants of store brand share", Journal of Retailing, Vol.90 No.2, pp.141-153.

Sinha S.K. and Verma P. (2018), "Impact of Sales Promotion's Benefits on Brand Equity: An Empirical Investigation." Global Business Review. Vol.9, No.6, pp.1663-1680.

Soininen, K. (2015), “Attitudes Towards Innovation in the Food Market - UK - July 2015”, available at: https://academic.mintel.com/display/716155/(accessed 11 March 2021).

Sullivan, G. M. and Feinn, R. (2012), “Using Effect Size-or Why the P Value Is Not Enough”, Journal of Graduate Medical Education, Vol.4 No.3, pp.279-282. 
terBraak, A., Geyskens, I. and Dekimpe, M.G. (2014), “Taking private labels upmarket: empirical generalizations on category drivers of premium private label introductions", Journal of Retailing, Vol 90 No.2, pp.125-140.

Valaskova, K., Kliestikova, J. and Krizanova, A. (2018), "Consumer perceptions of private label products: an empirical study", Journal of Competitiveness, Vol.10 No.3, pp.149-163.

Wells, L.E., Farley, H. and Armstrong, G.A. (2007), “The importance of packaging design for own-label food brands", International Journal of Retail \& Distribution Managaement, Vol 35 No.9, pp.677-690.

Winit, W., Gregory, G., Cleveland, M. and Verlegh, P. (2014), "Global vs local brands: how home country bias and price differences impact brand evaluations", International Marketing Review, Vol.31 No.2, pp.102-128.

Zoellner, F. and Schaefers, T. (2015), "Do price promotions help or hurt premium-product brands", Journal of Advertising Research, Vol.55 No.3, pp.270-283. 